\title{
Clinical Spectrum of congenital heart defects (CHD) detected at the child health Clinic in a Tertiary Health Facility in Ghana: a retrospective analysis
}

Nicholas Ekow Thomford ${ }^{1,2^{*}}$ (D), Robert Peter Biney ${ }^{3}$, Emmanuel Okai $^{4}$, Akwasi Anyanful $^{2}$, Paul Nsiah $^{5}$, Prosperity G. Frimpong ${ }^{2}$, Dominic O. Boakye ${ }^{2}$, Charles A. Adongo ${ }^{6}$, Paul Kruszka ${ }^{7}$ and Ambroise Wonkam ${ }^{1}$

\begin{abstract}
Background: Congenital heart defects (CHD) are the singular most common congenital anomalies and account for a significant fraction of childhood mortality and morbidity. CHD occurs in 1\% of livebirths globally and often requires surgical interventions to improve quality of life and survival of patients. The prevalence and clinical presentations of CHD within specific populations provide a clearer overview of the burden of CHD and informs appropriate interventions. However, there is limited data on clinical presentation and occurrence of CHD in African countries such as Ghana where most cases are either diagnosed late or missed entirely resulting in increased mortality. In this retrospective study, we assessed the clinical presentations, associated comorbidities, and prescription patterns of diagnosed CHD in a tertiary facility in Ghana.

Method: This retrospective study utilized data from electronic health records (EHR) from the child health clinic of the Cape Coast Teaching Hospital - a tertiary health facility in Ghana from January 2018 to October 2019. All suspected or provisionally diagnosed cases including those confirmed with echocardiography were included in our analysis.

Results: Over 10, 000 records were reviewed, CHD was diagnosed in 79 cases, and 51 cases had complete clinical records including the type of CHD and clinical presentation. Male to female ratio was approximately 1:1 and 77.2\% of the diagnoses were in children below 5 years. Acyanotic congenital heart defects were most commonly diagnosed with ventricular septal defects (VSD) and patent ductus arteriosus (PDA) being the simplest singular CHD. Tetralogy of Fallot, was the most common complex CHD accounting for 25.5\% (13) of cases. Bronchopneumonia, upper respiratory infections and pneumonia were the most commonly diagnosed comorbidities accounting for over 35\% of non-cardiac sequalae based on antibiotic and diuretic use.

(Continued on next page)
\end{abstract}

\footnotetext{
* Correspondence: nicholas.thomford@uct.ac.za

'Division of Human Genetics, Department of Pathology and Institute of

Infectious Diseases and Molecular Medicine, Faculty of Health Sciences,

University of Cape Town, Anzio Road, Observatory, 7925 Cape Town, South

Africa

${ }^{2}$ Department of Medical Biochemistry, School of Medical Sciences, College of

Health and Allied Sciences, University of Cape Coast, PMB, Cape Coast,

Ghana

Full list of author information is available at the end of the article
}

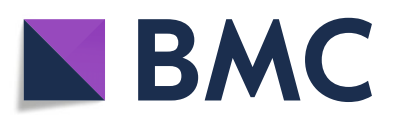

(c) The Author(s). 2020 Open Access This article is licensed under a Creative Commons Attribution 4.0 International License, which permits use, sharing, adaptation, distribution and reproduction in any medium or format, as long as you give appropriate credit to the original author(s) and the source, provide a link to the Creative Commons licence, and indicate if changes were made. The images or other third party material in this article are included in the article's Creative Commons licence, unless indicated otherwise in a credit line to the material. If material is not included in the article's Creative Commons licence and your intended use is not permitted by statutory regulation or exceeds the permitted use, you will need to obtain permission directly from the copyright holder. To view a copy of this licence, visit http://creativecommons.org/licenses/by/4.0/. The Creative Commons Public Domain Dedication waiver (http://creativecommons.org/publicdomain/zero/1.0/) applies to the data made available in this article, unless otherwise stated in a credit line to the data. 
(Continued from previous page)

Conclusion: Our study showed that over $75 \%$ of CHD cases were diagnosed under 5 years with VSD and TOF being the most commonly diagnosed acyanotic and cyanotic lesions, respectively. This study presents preliminary data that give an overview of CHD burden in Ghana that will inform future research and appropriate interventions.

Keywords: Congenital heart defects, Cardiovascular complications, Ventricular septal defect, Clinical presentation, Ghana, Tetralogy of Fallot

\section{Background}

Congenital heart defects (CHD) are the most common congenital birth defects affecting $1-2 \%$ of all live births globally with an estimated incidence of $8-10 / 1000$ live births [1-3]. There are regional differences in prevalence and incidence due to genomic, clinical and environmental factors $[4,5]$. CHD is defined by structural and functional malformations of the heart which if not managed through appropriate interventions affects quality of life of the individual and potential premature death. Early detection, diagnosis and prompt interventions result in significantly decreased morbidity and mortality $[6,7]$. The estimated incidence of CHD is similar across all countries globally $[1,8]$; however, CHD data for African countries is sparse and needed [4]. CHD malformations occur as single lesions or in combination with other heart defects [9]. Commonly diagnosed CHD lesions isolated or single lesions include atrial septal defects (ASD), ventricular septal defects (VSD), and pulmonary stenosis (PS). Complex or combination lesions include atrioventricular septal defects (AVSD), tetralogy of Fallot (TOF), and transposition of the great arteries (TGA) [911]. TOF and TGA are the two most common cyanotic CHD conditions that result in oxygen saturation below $90 \%$. Majority of septal defects such as VSD, ASD and AVSD are classified as acyanotic CHD lesions with oxygen saturation normally above $95 \%$.

Congenital heart defects are commonly associated with genetic syndromes including but not limited to Down syndrome, Turner syndrome, 22q11.2 deletion syndrome, 1 p36 deletion syndrome and Noonan syndrome. Most often, CHD is sporadic, not associated with a syndrome, and of unknown etiology. Few CHD studies have been published in Ghana [12,13], and the rare reported cases do not include prevalence data, which is important to low resource countries such as Ghana where very few children with CHD get detected early and receive timely corrective surgery [14-16]. Due to delayed diagnosis and intervention, these children may develop complications such as heart failure, severe cyanosis and other longterm sequelae [17-19]. Other non-cardiac complications arise from infections, malnutrition and adverse events from administered medications [20-22]. Clearly, there is a need for data on clinical presentation, CHD severity and phenotype from tertiary facilities in Ghana. For these reasons, we therefore conducted a retrospective study to determine the spectrum and clinical presentations of CHD among children receiving care at the Cape Coast Teaching Hospital (CCTH), Cape Coast, Ghana. This is the largest tertiary facility providing specialized services to the Western and Central regions of Ghana. Results from our study will help will provide the baseline data that can inform designing genomics and molecular studies aimed at understanding the CHD burden and profile in Ghana. This study will also facilitate a registry for CHD with the goal of increased monitoring and better management.

\section{Methods}

This hospital based retrospective study was conducted at the Cape Coast Teaching Hospital (CCTH), Cape Coast, Ghana. The facility is a referral center with a 400-bed capacity and offers echocardiography services three times in a week which is not covered by the National Health Insurance Scheme (NHIS) of Ghana. CCTH sees to approximately 3000 children annually. The hospital upgraded its patient's records system to an electronic health records (EHR) system in January 2018 where patient data such as age, gender, clinic visited, diagnosis, medication and laboratory investigations are recorded and stored digitally. Between the period of January 2018 and October 2019, electronic health records of children between the ages of $0-16$ years who presented at the child health clinic were queried. Data on analysis focused on patients who had undergone echocardiography and also had history and exam information available.

\section{Data extracted}

Data extracted from the EHR included age, clinical presentation, CHD type, national health insurance status, prescribed medication, comorbidities and oxygen saturation profile. Patients with incomplete data were excluded.

\section{Data analysis}

Statistical analysis was performed with STATA Statistical Software: Release 15 (StataCorp. 2017) and GraphPad prism 8 (GraphPad Software, San Diego California, USA). 


\section{Results}

\section{Patients characteristics}

Table 1 shows the patient characteristics. There a total of over 10,000 hospital visits at the child health clinic and seventy-nine children diagnosed with CHD by a cardiologist were included in this study. From the 79 diagnosed cases, complete data on CHD type with relevant clinical information was available for 51 children and was thus used in subsequent analysis (Fig. 1). The male to female ratio of approximately $1: 1$ and the median age was 1.9 years (range -3 months-16 years) (Table 1$)$. Most patients were below the age of 5 years $(61 / 79), 77.2 \%$. Of the patients who were diagnosed with $\mathrm{CHD}, 58 \%$ were insured under the National Health Insurance Scheme of Ghana (NHIS).

\section{CHD profile}

Table 2 summarizes specific CHD malformation prevalence and Table 3 stratifies CHD types by age. CHD lesions that resulted in cyanosis were observed in (19/ 51), $37.3 \%$ of the patients. The majority CHD (86\%) were isolated cases not associated dysmorphic or syndromic features. Simple CHD lesions accounted for $45.1 \%$ of all cases diagnosed while complex lesions were $54.9 \%$ (Table 2).

The most common acyanotic CHD was ventricular septal defects affecting $31.4 \%$ of diagnosed children with TOF being the commonest cyanotic CHD (25.5\%). The data obtained in this study, although comparable with similar studies, shares some variances with a other studies (Table 4). Some multiple CHDs were reported for the first time whiles other already reported had lower prevalence. However, one thing that stands out is the significance of TOF prevalence in these developing countries where these studies were conducted.

\section{Clinical presentations}

Common clinical presentations associated with the diagnosed congenital heart defects were dyspnea (6.4\%), cyanosis (17.8\%), coughing (10.2), fever (8.3\%), murmur (3.8\%), pallor $(3.82 \%)$ and tachypnea $(5.7 \%)$. For each of the CHD types, common clinical presentations as observed are shown in Fig. 2 in graphical form.

Pulse oximetry measurement to determine oxygen saturation $\left(\mathrm{SPO}_{2}\right)$ for each $\mathrm{CHD}$ type established the need for routine $\mathrm{SPO}_{2}$ measurements for patients (Fig. 3). Multiple lesion cyanotic CHD types had an average oxygen saturation of $<95 \%$ with TOF (48.61-65.06\%) and TGA (75.89-85.66\%) being the commonest lesions (Table 5).

Comorbidities associated with CHD in diagnosed children Among the diagnosed CHD children only 7 (13.7\%) had syndromic features which was Down syndrome. Significant comorbidities seen in the children diagnosed with CHD were grouped into systems such as cardiovascular $(n=5)$, hematological conditions $(n=6)$, inflammatory/ infectious $(n=12)$, pulmonology $(n=34)$, and parasitic infections $(n=5)$. Table 6 shows the prevalent comorbidities and their distribution. The commonest

Table 1 Demographic characteristics of diagnosed congenital heart defects subjects

\begin{tabular}{|c|c|c|}
\hline Variable & Mean \pm SE (95\% Conf. Interval) & No. (\%) \\
\hline \multicolumn{3}{|l|}{ Age range (years) } \\
\hline$<1$ & $0.40 \pm 0.07(0.26-0.53)$ & $21(26.58)$ \\
\hline $1-5$ & $2.10 \pm 0.15(1.81-2.39)$ & $40(50.63)$ \\
\hline $6-10$ & $7.36 \pm 0.47(6.42-8.30)$ & $11(13.92)$ \\
\hline $11-16$ & $13.86 \pm 1.20(11.46-16.25)$ & $7(8.86)$ \\
\hline \multicolumn{3}{|l|}{ Gender } \\
\hline Male & & $38(48.10)$ \\
\hline Female & & $41(51.90)$ \\
\hline \multicolumn{3}{|l|}{ NHIS status } \\
\hline Insured & & $46(58.23)$ \\
\hline Non-insured & & $33(41.77)$ \\
\hline \multicolumn{3}{|l|}{ Chromosomal anomalies } \\
\hline Down syndrome associated CHD & & $7(13.7)$ \\
\hline Isolated CHD & & $44(86.3)$ \\
\hline \multicolumn{3}{|l|}{ CHD type } \\
\hline Acyanotic & & $32(62.75)$ \\
\hline Cyanotic & & $19(37.25)$ \\
\hline
\end{tabular}




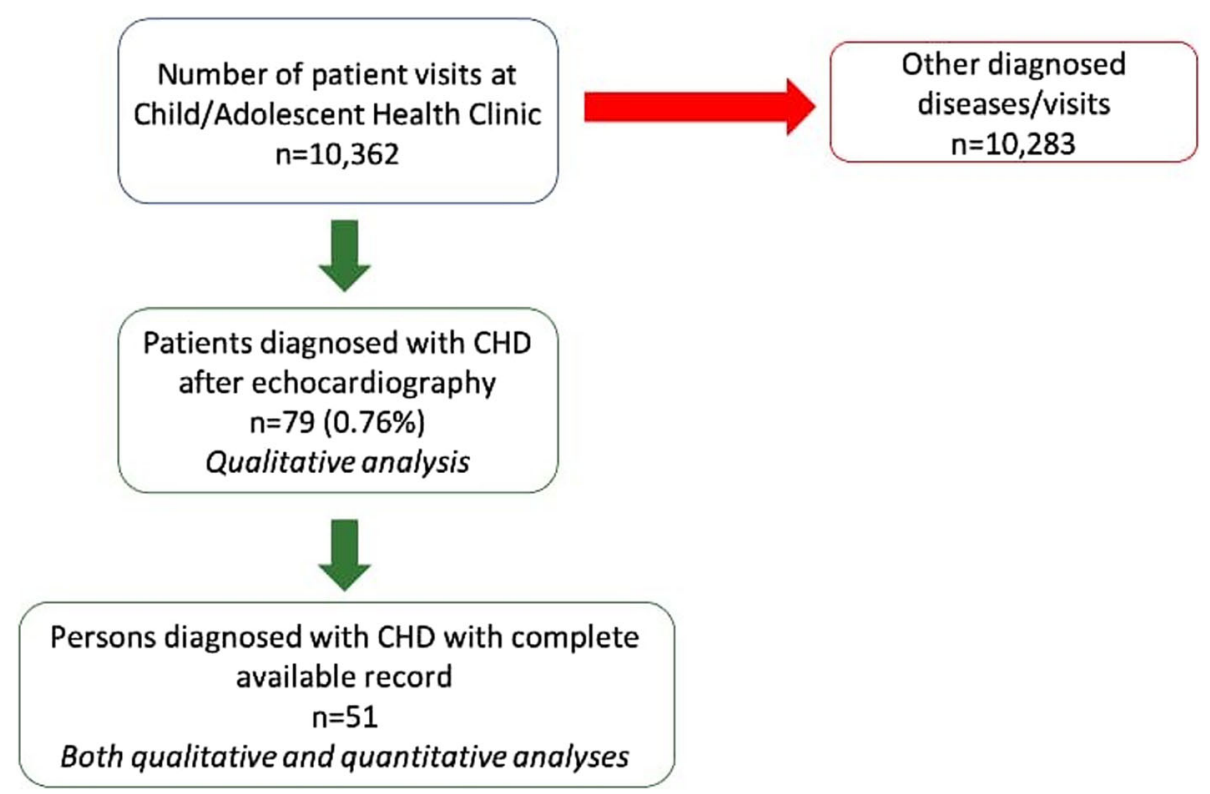

Fig. 1 Flow chart of cases recorded, diagnosed with CHD and numbers included in analysis, CHD, congenital heart defects

Table 2 Diagnosed single and multiple lesions in children with congenital heart defects

\begin{tabular}{|c|c|c|}
\hline & Type of CHD & No (\%) \\
\hline \multirow[t]{4}{*}{ Simple lesions } & VSD & $16(31.4)$ \\
\hline & PDA & $3(5.9)$ \\
\hline & PS & $3(5.9)$ \\
\hline & ASD & $1(2.0)$ \\
\hline Sub-total & & $23(45.09)$ \\
\hline \multirow[t]{14}{*}{ Complex lesions } & TOF & $13(25.5)$ \\
\hline & AVSD & $2(3.9)$ \\
\hline & VA & $2(3.9)$ \\
\hline & TGA & $1(2.0)$ \\
\hline & AV malformation & $1(2.0)$ \\
\hline & $\mathrm{RAH}+\mathrm{RV}$ & $1(2.0)$ \\
\hline & $T A+R A H+T R$ & $1(2.0)$ \\
\hline & $\mathrm{TGA}+\mathrm{TOF}$ & $1(2.0)$ \\
\hline & $T A+P A+P L S V C+P S$ & $1(2.0)$ \\
\hline & TOF + PDA & $1(2.0)$ \\
\hline & $\mathrm{TS}++\mathrm{VSD}+\mathrm{AV}+\mathrm{TR}$ & $1(2.0)$ \\
\hline & $\mathrm{TS}+\mathrm{AV}$ malformation & $1(2.0)$ \\
\hline & $V A+A V$ & $1(2.0)$ \\
\hline & $V S D+P A S$ & $1(2.0)$ \\
\hline Sub-total & & $28(54.90)$ \\
\hline Total & & 51 \\
\hline
\end{tabular}

Footnote: AVSD Atrioventricular Septal Defect, PAS Stenosis of pulmonary artery, PS Pulmonary valve stenosis, VSD Ventricular septal defect, TOF

Tetralogy of Fallot, PDA Patent ductus arteriosus, ASD Atrial septal defect, TGA

Transposition of the great arteries, $V A$ Ventriculoarterial concordance, $R A H$

Right atrial hypertrophy, RV Dilated right ventricle, AV Atrioventricular

concordance, TR Tricuspid regurgitation, PLSVC Persistent left superior vena

cava, PA Pulmonary atresia, TA Tricuspid atresia, TS Tricuspid, Stenosis
Table 3 Distribution of CHD types with age among the children

\begin{tabular}{llllll}
\hline TYPE OF CHD & \multicolumn{4}{l}{ AGE RANGE (YEARS) } & TOTAL \\
\cline { 2 - 5 } & $<\mathbf{1}$ & $\mathbf{1 - 5}$ & $\mathbf{6 - 1 0}$ & $\mathbf{1 1 - 1 6}$ & \\
\hline
\end{tabular}

Simple lesions

VSD

PDA

PS

ASD

Complex lesions

TOF

AVSD

VA

AV malformation

TGA

$\mathrm{RAH}+\mathrm{RV}$

$T A+P A+P L S V C+P S$

$\mathrm{TA}+\mathrm{RAH}+\mathrm{TR}$

TGA + TOF

TOF + PDA

$\mathrm{TS}+\mathrm{AV}$ malformation

$T S+V S D+A V+T R$

$\mathrm{VA}+\mathrm{AV}$

VSD + PAS

Total

12

25

7

7

$\begin{array}{llll}12 & 25 & 7 & 7\end{array}$


Table 4 Comparative study of current lesions with other studies

\begin{tabular}{llllllll}
\hline Type of CHD & Current study & {$[23]$} & {$[24]$} & {$[25]$} & {$[26]$} & {$[27]$} & {$[28]$} \\
\hline & $(\%$ rep./study) & & & & & & \\
ASD & 2.0 & 25.4 & 22.9 & 16.9 & 9.3 & 18.8 & 14.7 \\
AV malformation & 2.0 & 3.0 & 4.1 & - & - & 2.3 & 0.7 \\
AVSD & 3.9 & - & - & 10.3 & - & 9.8 & - \\
PAS + PS & 2.0 & - & - & - & - & - & - \\
PDA & 5.9 & 6.0 & 23.9 & 16.9 & & 8.6 & 9.5 \\
PS & 5.9 & 6.7 & 7.3 & - & 3.1 & 5.1 & 5.0 \\
RAH + RV & 2.0 & - & - & - & - & - & - \\
TA + PA+ PLSVC + PS & 2.0 & - & - & - & - & - & - \\
TA + RAH + TR & 2.0 & - & - & - & - & - & - \\
TGA & 2.0 & 5.2 & 27.0 & 31.3 & 4.1 & 3.4 & 2.0 \\
TGA + TOF & 2.0 & - & - & - & - & - & - \\
TOF & 25.5 & 9.5 & 48.0 & 51.7 & 24.4 & 24.4 & 18.0 \\
TOF + PDA & 2.0 & 3.7 & - & - & - & - & - \\
TS + AV malformation & 2.0 & - & - & - & - & - & - \\
TS + VSD + AV + TR & 2.0 & - & - & - & - & - & - \\
VA & 3.9 & - & - & - & - & - & - \\
VA + AV & 2.0 & - & - & - & - & - & - \\
VSD & 31.4 & 29.9 & 31.4 & 33.8 & 28.0 & 21.5 & 38.0 \\
VSD + PAS & 2.0 & - & - & - & - & - & - \\
\hline
\end{tabular}

comorbidities observed in CHD patients was bronchopneumonia (16.48\%) and upper respiratory tract infection $(9.89 \%)$. During the period under consideration death occurred in 4 children (5.06\%) from CHD and related complications.

\section{Prescription patterns for managing CHD and comorbidities}

The prescription pattern based on diagnosis and comorbidities showed a prescription pattern of significant numbers for antibiotics and diuretics (Table 7) with the commonest one being gentamicin [21], benzylpenicillin [20], furosemide [29] and spironolactone [14]. Non-steroidal anti-inflammatory drugs and supplements were also commonly prescribed to CHD patients admitted to the facility.

Other classes of antibiotics were prescribed for the various comorbidities and some to help mitigate the complications of CHD (Fig. 4).

\section{Discussion}

The accepted global approximation of CHD is $~ 1 \%$ of livebirths [1-3] and in this study, the overall hospital prevalence of CHD encountered was $<1 \%$ which is consistent with global prevalence. This study retrospectively analyzed CHD incidences and clinical characteristics from a tertiary health facility in Ghana making it the first study of its kind in Ghana, which is important for low resource settings such as Ghana where this provides a

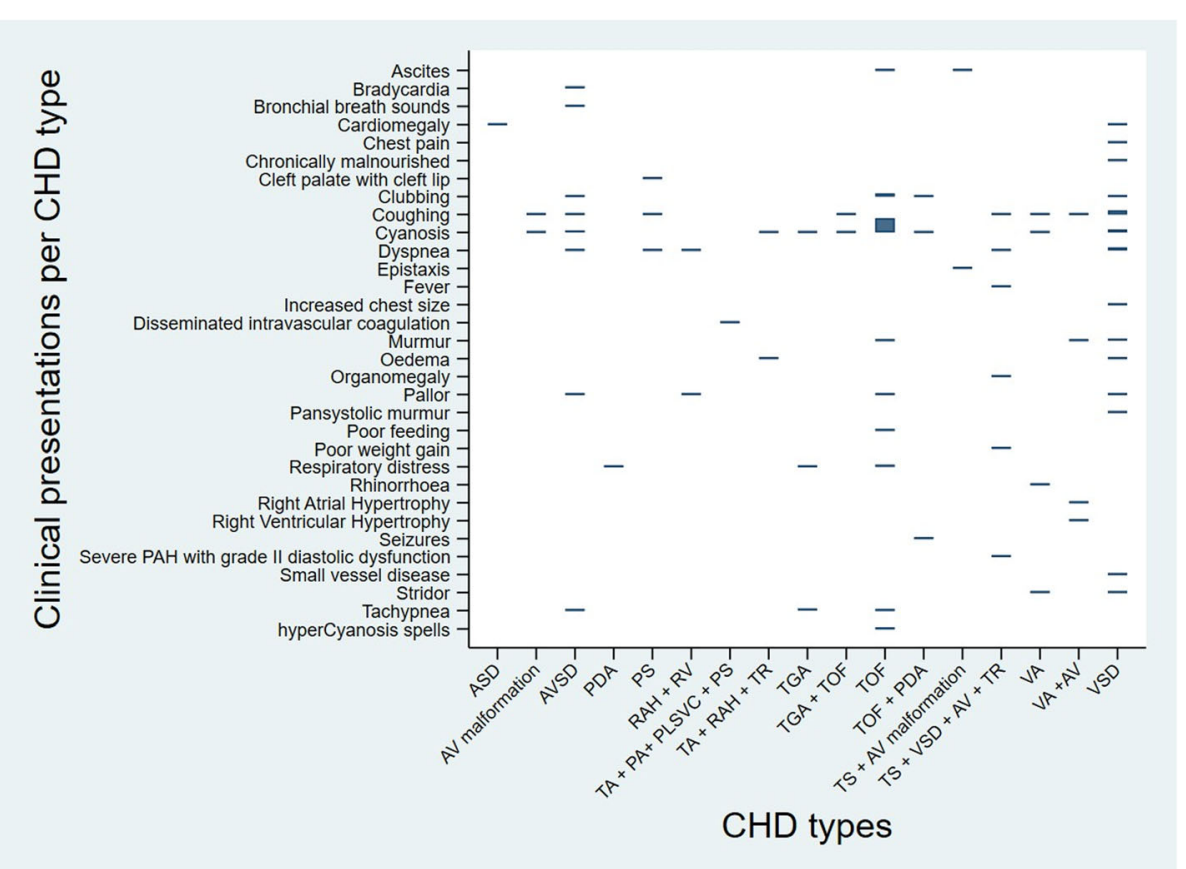

Fig. 2 Clinical presentations associated with CHD types in diagnosed Children; Box thickness indicates numbers exhibiting clinical symptom. Pulmonary arterial hypertension (PAH) 


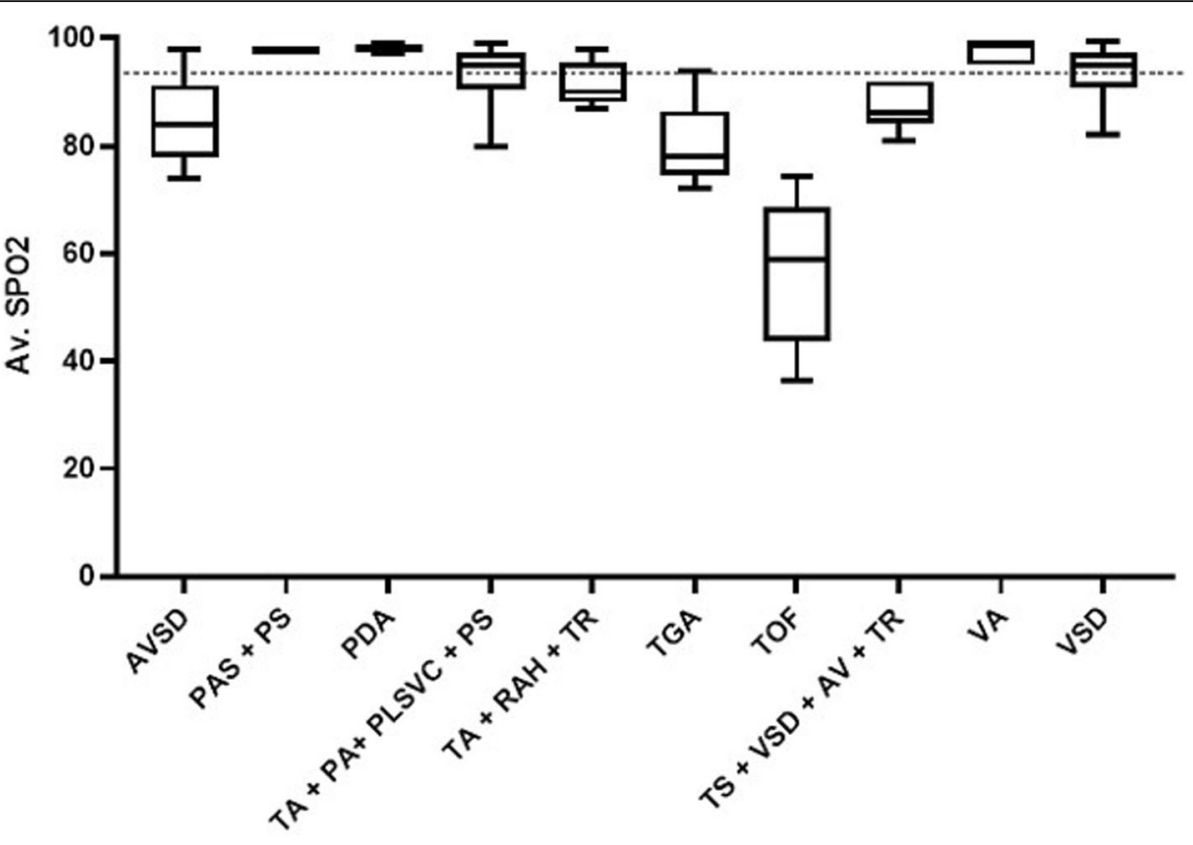

CHD Phenotypes

Fig. 3 Average pulse oximetry readings (SPO2) with CHD types in diagnosed Children. CHD, Congenital heart defects; SPO2, peripheral capillary oxygen saturation

basis for further studies and appropriate clinical interventions. This study demonstrates the value of an accurate EHR, especially as we lost almost a third of the data due to incomplete entries. We obtained data for 22 months from an electronic health records database from the hospital to be able to conduct this analysis. In terms of actual numbers, the incidence of congenital heart defects was low for the two-year period due to the unavailability of data for earlier years (paper records were being used up until 2018), however, percentage-wise, the types and clinical symptoms obtained were comparable with published studies from other jurisdictions as observed in our comparative analysis.

Table 5 Mean SPO2 readings with CHD lesion type

\begin{tabular}{ll}
\hline CHD type & Mean \pm SE (95\% Conf. Interval) \\
\hline AVSD & $84.70 \pm 2.67(79.39-90.01)$ \\
PDA & $98.01 \pm 0.13(97.23-99.65)$ \\
VSD & $96.08 \pm 1.60(94.89-97.27)$ \\
TGA & $80.78 \pm 2.45(75.89-85.66)$ \\
TOF & $56.83 \pm 4.13(48.61-65.06)$ \\
VA & $97.67 \pm 0.84(95.99-99.34)$ \\
TA + PA+ PLSVC + PS & $93.33 \pm 1.94(89.48-97.18)$ \\
TA + RAH + TR & $91.33 \pm 1.33(88.68-93.99)$ \\
PAS + PS & $97.50 \pm 0.28(96.93-98.07)$ \\
TS + VSD + AV + TR & $86.90 \pm 1.28(84.36-89.44)$ \\
\hline
\end{tabular}

In the present analysis, $26.58 \%$ children diagnosed with CHD were below 1 year old with the majority of those diagnosed falling between the 1-5-year group (50.63\%). Gender distribution was approximately the same (1:1) which compares with other studies previously reported in India and Nigeria [29, 30]. Our data however, showed a slight majority of females with CHD being diagnosed at the facility. As observed in this study, isolated CHD accounted for $86.3 \%$ which is comparable with other reported proportions in Egypt and India [31, 32]. The commonest syndrome diagnosed in addition to CHD was Down syndrome. Cyanotic to acyanotic CHD ratio was 1: 1.6 which makes acyanotic $\mathrm{CHD}$ the most diagnosed. The trend is what is mostly encountered globally, where most of the CHD diagnosed are acyanotic in nature. Ghana has a well instituted national health insurance scheme that covers majority of conditions at affordable cost excluding CHD management. Our data indicated that 58.23\% percent of patients were captured under health insurance however, the scheme does not cover imaging investigations such as echocardiography and cardiac computer tomography (cCT) scan which makes it difficult for further investigations to be conducted once CHD is suspected.

The commonest CHD diagnosed at the facility were ventricular septal defects (31.4\%) and PDA (5.88\%) which is similar to reported cases in other low resource countries as shown in Table $4[23,26,33]$. The 
Table 6 Prevalence of comorbidities diagnosed in CHD patients

\begin{tabular}{|c|c|c|}
\hline Subspecialty & Comorbidity & No. Patients (\%) \\
\hline \multirow[t]{4}{*}{ Cardiovascular $n=5$} & Heart failure & $2(2.2 \%)$ \\
\hline & Dilated cardiomyopathy & $1(1.1 \%)$ \\
\hline & Segmental arterial mediolysis & $1(1.1 \%)$ \\
\hline & Valvular heart disease & $1(1.1 \%)$ \\
\hline \multirow[t]{2}{*}{ Gastroenterology $n=3$} & Congenital tracheoesophageal fistula & $2(2.20)$ \\
\hline & Gastroesophageal Reflux & $1(1.1 \%)$ \\
\hline \multirow[t]{5}{*}{ Hematological conditions $n=6$} & Anaemia & $2(2.20)$ \\
\hline & Haemorrhagic disease & $1(1.1 \%)$ \\
\hline & Heamophilic condition & $1(1.1 \%)$ \\
\hline & Desseminated intravascular coagulation & $1(1.1 \%)$ \\
\hline & Polycythaemia & $1(1.1 \%)$ \\
\hline \multirow[t]{2}{*}{ Orthopedics $n=2$} & Myoclonic jerks & $1(1.1 \%)$ \\
\hline & Nondisplaced avulsion fracture & $1(1.1 \%)$ \\
\hline \multirow[t]{2}{*}{ Neurology $n=2$} & Epilepsy & $1(1.1 \%)$ \\
\hline & Seizures & $1(1.1 \%)$ \\
\hline Nephro-urology $n=1$ & Urinary tract infection & $1(1.1 \%)$ \\
\hline \multirow[t]{7}{*}{ Pulmonology $n=34$} & Acute Bronchitis & $1(1.1 \%)$ \\
\hline & Bronchiolitis & $1(1.1 \%)$ \\
\hline & Bronchopneumonia & $15(16.5 \%)$ \\
\hline & Bacterial pneumonia & $1(1.1 \%)$ \\
\hline & Upper respiratory infection & 9 (9.89\%) \\
\hline & Pneumonia & $5(5.49)$ \\
\hline & Pulmonary/respiratory tuberculosis & $2(2.20 \%)$ \\
\hline \multirow[t]{7}{*}{ Inflammatory/infectious $n=12$} & Sepsis & $3(3.30)$ \\
\hline & Conjunctivitis & $2(2.2 \%)$ \\
\hline & Infective endocarditis & $2(2.20)$ \\
\hline & Meningitis & $2(2.2 \%)$ \\
\hline & Acute tonsillitis & $1(1.1 \%)$ \\
\hline & Gastroenteritis and colitis & $1(1.1 \%)$ \\
\hline & Pharyngitis & $1(1.1 \%)$ \\
\hline Parasitic infections $n=5$ & Plasmodium falciparum malaria & $5(5.49)$ \\
\hline \multirow[t]{9}{*}{ Other conditions $n=15$} & Malnutrition & $7(7.7 \%)$ \\
\hline & Immunosuppression & $1(1.1 \%)$ \\
\hline & Birth asphyxia & $1(1.1 \%)$ \\
\hline & Tinea barbae and tinea capitis & $1(1.1 \%)$ \\
\hline & Infantile papular acrodermatitis & $1(1.1 \%)$ \\
\hline & Hemopentoneum & $1(1.1 \%)$ \\
\hline & Hypothermia & $1(1.1 \%)$ \\
\hline & Nonsuppurative otitis media & $1(1.1 \%)$ \\
\hline & Epigastric pain & $1(1.1 \%)$ \\
\hline
\end{tabular}

commonest single cyanotic CHD lesion observed was tetralogy of Fallot (25.5\%) which is analogous to studies conducted in low resource countries [27, 33]. Without corrective surgery, only $24 \%$ of patients with TOF with or without other lesions such as PDA live to age 10 years [34], with very few living past 20 years [35]. However, early diagnosis and corrective surgery changes this dismal survival rate in cyanotic lesions such as CHD [36]. 
Table 7 List of 7 commonly prescribed medications for diagnosed CHD patients

\begin{tabular}{llll}
\hline Medication & Class & Usage in Cardiac conditions & Frequency \\
\hline Furosemide & Diuretic & Heart failure & 24 \\
Gentamicin & Antibiotic & - & 21 \\
Benzylpenicillin & Antibiotic & - & 20 \\
Multivitamin supplements & Supplements & - & 19 \\
Paracetamol & Non-steroidal anti-inflammatory drug & - & 14 \\
Spironolactone & Diuretic & Heart failure & 14 \\
Cefuroxime & Antibiotic & - & 12 \\
\hline
\end{tabular}

In countries such as Ghana, improved infrastructure has led to accurate diagnosis however, access to corrective surgery especially in children is still challenging due to financial reasons and professional expertise requiring most families to seek the right intervention outside the country, reducing the survival rate of patients diagnosed with cyanotic CHD lesions. During the period under consideration, 4 (5.06\%) children died from CHD related complications and late interventions.

Pulse oximetry (PO) measurements have been recommended as a routine screening method for newborns to be able to detect cyanotic CHD lesions early and take appropriate interventions [37, 38]. In Ghana PO measurement is not routinely done. PO measurement is high specific and helps in reducing discharge of apparently healthy patients with unknown CHD by approximately 6\% more likely in cyanotic CHD lesions and other serious multiple CHD lesions [39-41]. Analysis of PO readings for diagnosed $\mathrm{CHD}$ children at our facility indicated $\mathrm{SPO}_{2}$ levels of $<95 \%$ for common cyanotic lesions such as TGA and TOF and multiple CHD lesions (Table 5) reinforcing the need for routine $\mathrm{PO}$ measurements in addition to clinical examination for CHD detection improvement (Fig. 3). Other common clinical presentations such as dyspnea, cyanosis, coughing, tachypnea and murmur were observed in CHD diagnosed children at the facility. For countries such as Ghana with a low doctor to patient ratio, PO measurements in addition to a look out for some of these clinical presentations such as murmur which has pathologic character will enhance early detection and intervention and is thus strongly recommended by this study.

CHD is often associated with non-cardiac complications which also makes interventional measures multifaceted $[42,43]$.. In our study, we observed that $37 \%$ of diagnosed patients had diseases associated with the

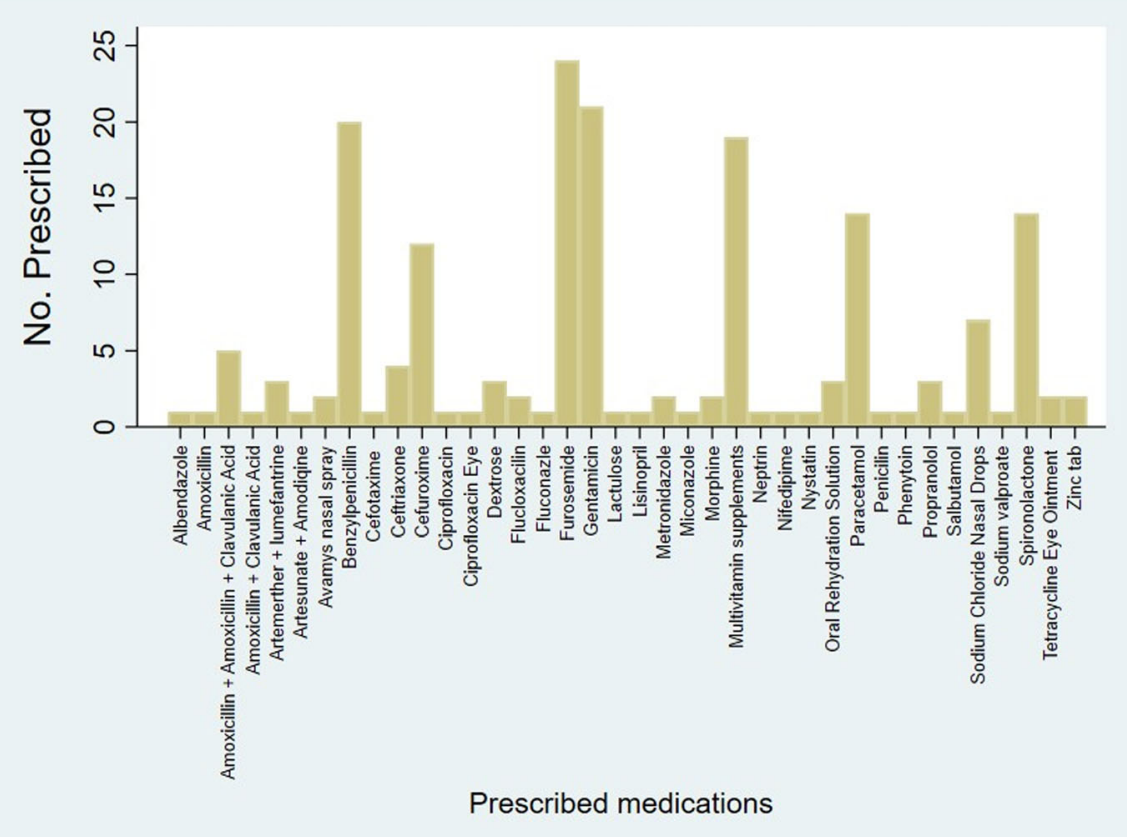

Fig. 4 Prescription patterns for CHD patients 
respiratory tract (pulmonology) with the most common being bronchopneumonia (16.5\%). These CHD associated complications may be the initial presentation of CHD and should alert the physician to consider CHD in the differential diagnosis. Some of these treatments also exacerbates the clinical presentations of CHD. Prescription pattern for managing both $\mathrm{CHD}$ and comorbidities indicated that, antibiotics and diuretics were the most common medicines prescribed in addition to nonsteroidal anti-inflammatory drugs and supplements (Table 7). These classes of drugs have been shown to help manage some of the CHD clinical presentations in addition to comorbidities such as bronchopneumonia and heart failure [44]. According to the Ghana Standard Treatment Guidelines (GSTG), pharmacological treatments suggested for TOF are $250 \mu \mathrm{g}-1 \mathrm{mg} / \mathrm{kg}$ propranolol 6-8 hourly, 2-3 mg/Kg/day spironolactone and 1-2 $\mathrm{mg} / \mathrm{Kg}$ furosemide daily for heart failure [45]. In this study, we found the prescription of furosemide and spironolactone in about 20\% of diagnosed CHD patients which was in accordance with the guidelines. However, agents such as propranolol, nifedipine, phenytoin and lisinopril which are indicated for the management of cardiac conditions such as heart failures and arrythmias were found to be lowly prescribed $(<1 \%)$. The pattern indicated a focus on treatment for comorbid bronchopneumonia other than cardiac related conditions. The guidelines only provide recommendations for the management of TOF however, recommendation for other common CHD types identified in the study such as VSD were not available it the GSTG and we recommend their inclusion. Our study has made an attempt to analyze prescription patterns among children with CHD in a developing country.

The prevalence of CHD types observed in this study is comparable to other studies published in both developed and developing countries (Table 4). However, ASD, a largely asymptomatic lesion was only found in $2 \%$ of the CHD patients. This could be because isolated ASD is rarely diagnosed in neonates and it is seen that diagnosis was made in the 6-10-year-old group in this study. Although more and more ASDs are being diagnosed and closed during childhood, many are still only first identified in adult life or even in old age [46].Such data has enabled interventional measures and management of CHD resulting in an increased survival rate for children born with CHD irrespective of type most especially isolated incidences. For congenital heart defect management, early detection leads to early diagnosis and management which improves the survival outcome of patients $[47,48]$. Our study shows that the average age at diagnosis for infants (less than 1 year of age) was 4 months, which allows for sufficient time to intervene surgically. A major limitation encountered in this study was the loss of data for previous years, as the EHR database was commenced in 2018 at the facility and also echocardiography services which helps in diagnoses was started within the same period. Looking at the data we have collected and the limitations provided, a comprehensive registry which seeks to gather data on CHD patients with specifically designed tools to collect data will help address some of these limitations. Such as registry will form a good basis for policy decisions and CHD management. This notwithstanding this analysis, provides preliminary data for monitoring, health auditing and policy interventions especially on routine pulse oximetry measurements and affordable echocardiography services.

\section{Conclusion}

In summary, we have presented a descriptive analysis on the spectrum, clinical presentations and prescription patterns of children born with CHD diagnosed at a tertiary health facility in Ghana. Key observations include $31.4 \%$ VSD and 25.5\% TOF cases encountered in the facility. Respiratory tract conditions were the most common comorbidities encountered with antibiotics and diuretics being common medications prescribed to children born with CHD at the facility. Studies such as this will be useful for health personnel and general practitioners to help with evaluating risk factors, early diagnosis and initiation of proper management as an overview of the prevalence and clinical presentation are provided in this study. Additionally, we show that pulse oximetry would greatly improve early CHD diagnosis in Ghana.

\section{Abbreviations}

CHD: Congenital heart defects; AVSD: Atrioventricular septal defect; PAS: Stenosis of pulmonary artery; PS: Pulmonary valve stenosis; VSD: Ventricular septal defect; TOF: Tetralogy of fallot; PDA: Patent ductus arteriosus; ASD: Atrial septal defect; TGA: Transposition of the great arteries; VA: Ventriculoarterial concordance; RAH: Right atrial hypertrophy; RV: Dilated right ventricle; AV: Atrioventricular concordance; TR: Tricuspid regurgitation; PLSVC: Persistent left superior vena cava; PA: Pulmonary atresia; TA: Tricuspid atresia; TS: Tricuspid, Stenosis

\section{Acknowledgements}

We acknowledge assistance of the MIS Department of CCTH for helping us retrieve data from the EHR database.

\section{Authors' contributions \\ NET conceptualized the study. NET, EO, RPK, AA, CAA, DOB and PGF extracted the data from the EHR. NET, RPK, CAA and EO drafted the manuscript and analyzed the data. PK, PN and AA commented on the manuscript. All authors looked at the final version and approved.}

\section{Funding}

This study is partly supported by the National Research Foundation of South Africa and the University of Cape Town through the incentive funding for rated researchers.

\section{Availability of data and materials}

The datasets generated and/or analysed during the current study can be requested from the authors on reasonable request. 


\section{Ethics approval and consent to participate}

The research protocol was approved by the ethical review committee (ERC) of the Cape Coast Teaching Hospital (CCTH) with reference number CCTH ERC/EC/2019/066. Written informed consent was not deemed necessary by the Review Board.

\section{Consent for publication}

Not applicable.

\section{Competing interests}

Authors declare no conflict of interest.

\section{Author details}

'Division of Human Genetics, Department of Pathology and Institute of Infectious Diseases and Molecular Medicine, Faculty of Health Sciences, University of Cape Town, Anzio Road, Observatory, 7925 Cape Town, South Africa. ${ }^{2}$ Department of Medical Biochemistry, School of Medical Sciences, College of Health and Allied Sciences, University of Cape Coast, PMB, Cape Coast, Ghana. ${ }^{3}$ Department of Pharmacology, School of Medical Sciences, College of Health and Allied Sciences, University of Cape Coast, PMB, Cape Coast, Ghana. ${ }^{4}$ Department of Pediatrics, School of Medical Sciences, College of Health and Allied Sciences, University of Cape Coast, PMB, Cape Coast, Ghana. ${ }^{5}$ Department of Chemical Pathology, School of Medical Sciences, College of Health and Allied Sciences, University of Cape Coast, PMB, Cape Coast, Ghana. ${ }^{6}$ Department of Hospitality \& Tourism Management, Data Economics and Policy, University of Cape Coast, Cape Coast, Ghana. National Human Genome Research Institute, Medical Genetics Branch, National Institutes of Health, Bethesda, MD, USA.

Received: 30 April 2020 Accepted: 21 July 2020

Published online: 03 August 2020

\section{References}

1. Liu Y, Chen S, Zuhlke L, Black GC, Choy MK, Li N, et al. Global birth prevalence of congenital heart defects 1970-2017: updated systematic review and meta-analysis of 260 studies. Int J Epidemiol. 2019;48(2):455-63.

2. van der Linde D, Konings EE, Slager MA, Witsenburg M, Helbing WA, Takkenberg JJ, et al. Birth prevalence of congenital heart disease worldwide: a systematic review and meta-analysis. J Am Coll Cardiol. 2011;58(21):2241-7.

3. Bakker MK, Bergman JEH, Krikov S, Amar E, Cocchi G, Cragan J, et al. Prenatal diagnosis and prevalence of critical congenital heart defects: an international retrospective cohort study. BMJ Open. 2019;9(7):e28139.

4. Jivanji SGM, Lubega S, Reel B, Qureshi SA. Congenital heart disease in East Africa. Front Pediatr. 2019:7:250

5. Thomford NE, Dzobo K, Yao NA, Chimusa E, Evans J, Okai E, et al. Genomics and Epigenomics of congenital heart defects: expert review and lessons learned in Africa. OMICS. 2018;22(5):301-21.

6. Yun SW. Congenital heart disease in the newborn requiring early intervention. Korean J Pediatr. 2011;54(5):183-91.

7. Carvalho JS. Antenatal diagnosis of critical congenital heart disease. Optimal place of delivery is where appropriate care can be delivered. Arch Dis Child. 2016;101(6):505-7.

8. Van Der Linde D, Konings EEM, Slager MA, Witsenburg M, Helbing WA, Takkenberg JJM, et al. Birth prevalence of congenital heart disease worldwide a systematic review and meta-analysis. JAC. 2011;58:2241-7.

9. van der Bom T, Zomer AC, Zwinderman AH, Meijboom FJ, Bouma BJ, Mulder BJ. The changing epidemiology of congenital heart disease. Nat Rev Cardiol. 2011;8(1):50-60.

10. Thiene G, Frescura C. Anatomical and pathophysiological classification of congenital heart disease. Cardiovasc Pathol. 2010;19(5):259-74.

11. Micheletti A. Congenital heart disease classification, epidemiology, diagnosis, treatment, and outcome. In: Flocco SF, Lillo A, Dellafiore F, Goossens $\mathrm{E}$, editors. Congenital heart disease: the nursing care handbook. Cham: Springer International Publishing; 2019. p. 1-67.

12. Edwin F, Zühlke L, Farouk H, Mocumbi AO, Entsua-Mensah K, Delsol-Gyan D, et al. Status and challenges of Care in Africa for adults with congenital heart defects. World J Pediatr Congenit Heart Surg. 2017;8:495-501.

13. Edwin F, Entsua-Mensah K, Sereboe LA, Tettey MM, Aniteye EA, Tamatey $\mathrm{MM}$, et al. Conotruncal heart defect repair in sub-Saharan Africa: remarkable outcomes despite poor access to treatment. World J Pediatr Congenit Heart Surg. 2016;7(5):592-9.
14. Ekenze SO, Jac-Okereke CA, Nwankwo EP. Funding paediatric surgery procedures in sub-Saharan Africa. Malawi Med J. 2019:31(3):233-40.

15. Edwin F, Tettey M, Aniteye E, Tamatey M, Sereboe L, Entsua-Mensah K, et al, The development of cardiac surgery in West Africa--the case of Ghana. Pan Afr Med J. 2011;9:15

16. Murala JSK, Karl TR, Pezzella AT. Pediatric cardiac surgery in low-and middleincome countries: present status and need for a paradigm shift. Front Pediatr. 2019;7:214.

17. Lui GK, Saidi A, Bhatt AB, Burchill L, Deen JF, Earing MG, et al. Diagnosis and Management of Noncardiac Complications in adults with congenital heart disease: a scientific statement from the American Heart Association. Circulation. 2017;136(20):e348-e92.

18. Mueller AS, McDonald DM, Singh HS, Ginns JN. Heart failure in adult congenital heart disease: tetralogy of Fallot. Heart Fail Rev. 2020.

19. Oliver Ruiz JM. Congenital heart disease in adults: residua, Sequelae, and complications of cardiac defects repaired at an early age. Rev Esp Cardiol (English Edition). 2003:56(1):73-88.

20. Ross F, Latham G, Joffe D, Richards M, Geiduschek J, Eisses M, et al. Preoperative malnutrition is associated with increased mortality and adverse outcomes after paediatric cardiac surgery. Cardiol Young. 2017;27(9):1716-25.

21. Ratanachu-Ek S, Pongdara A. Nutritional status of pediatric patients with congenital heart disease: pre- and post cardiac surgery. J Med Assoc Thai. 2011;94(Suppl 3):S133-7.

22. Murni IK, MacLaren G, Morrow D, lyer P, Duke T. Perioperative infections in congenital heart disease. Cardiol Young. 2017;27(S6):S14-21.

23. Mohammad N, Shaikh S, Memon S, Das H. Spectrum of heart disease in children under 5 years of age at Liaquat University Hospital, Hyderabad, Pakistan. Indian Heart J. 2014;66(1):145-9.

24. Wanni K, Shahzad N, Ashraf M, Ahmed K, Jan M, Rasool S. Prevalence and spectrum of congenital heart diseases in children. Heart India. 2014;2(3):76-9.

25. Bakhtyar Zahid S, Zeb Jan A, Ahmed S, Achakzai H. Spectrum of congenital heart disease in children admitted for cardiac surgery at Rehman medical institute, Peshawar, Pakistan. Pak J Med Sci. 2013;29(1):173-6.

26. Pate N, Jawed S, Nigar N, Junaid F, Wadood AA, Abdullah F. Frequency and pattern of congenital heart defects in a tertiary care cardiac hospital of Karachi. Pak J Med Sci. 2016:32(1):79-84.

27. Ekure EN, Kalu N, Sokunbi OJ, Kruszka P, Olusegun-Joseph AD, Ikebudu D, et al. Clinical epidemiology of congenital heart disease in Nigerian children, 2012-2017. Birth Defects Res. 2018;110(16):1233-40.

28. Abqari S, Gupta A, Shahab T, Rabbani M, Ali S, Firdaus U. Profile and risk factors for congenital heart defects: a study in a tertiary care hospital. Ann Pediatr Card. 2016;9(3):216-21.

29. Chinawa JM, Eze JC, Obi I, Arodiwe I, Ujunwa F, Daberechi AK, et al. Synopsis of congenital cardiac disease among children attending University of Nigeria Teaching Hospital Ituku Ozalla, Enugu. BMC Res Notes. 2013;6:475.

30. Meshram RM, Gajimwar VS. Prevalence, profile, and pattern of congenital heart disease in Central India: A prospective, observational study. Nig J Cardiol. 2018;15(1):45-9.

31. El-Gilany AH, Yahia S, Wahba Y. Prevalence of congenital heart diseases in children with Down syndrome in Mansoura, Egypt: a retrospective descriptive study. Ann Saudi Med. 2017;37(5):386-92.

32. Gokhroo RK, Gupta S, Arora G, Bisht DS, Padmanabhan D, Soni V. Prevalence of congenital heart disease in patients undergoing surgery for major gastrointestinal malformations: an Indian study. Heart Asia. 2015;7(1):29-31.

33. Abdulkadir M, Abdulkadir Z. A systematic review of trends and patterns of congenital heart disease in children in Nigeria from 1964-2015. Afr Health Sci. 2016;16(2):367-77.

34. Bertranou EG, Blackstone EH, Hazelrig JB, Turner ME, Kirklin JW. Life expectancy without surgery in tetralogy of Fallot. Am J Cardiol. 1978;42(3):458-66.

35. Yang X, Freeman L, Ross C. Unoperated tetralogy of Fallot: case report of a natural survivor who died in his 73rd year; is it ever too late to operate? Postgrad Med J. 2005;81(952):133-4.

36. Nollert G, Fischlein T, Bouterwek S, Böhmer C, Klinner W, Reichart B. Longterm survival in patients with repair of tetralogy of Fallot: 36-year follow-up of 490 survivors of the first year after surgical repair. J Am Coll Cardiol. 1997; 30(5):1374-83.

37. Kumar P. Universal pulse Oximetry screening for early detection of critical congenital heart disease. Clin Med Insights Pediatr. 2016;10:35-41.

38. Good RJ, Canale SK, Goodman RL, Yeager SB. Identification of critical congenital heart disease in Vermont: the role of universal pulse Oximetry screening in a rural state. Clin Pediatr. 2015;54(6):570-4. 
39. Mohsin M, Humayun KN, Atiq M. Clinical screening for congenital heart disease in newborns at a tertiary Care Hospital of a Developing Country. Cureus. 2019;11(6):e4808.

40. Gonzalez-Andrade F, Echeverria D, Lopez V, Arellano M. Is pulse oximetry helpful for the early detection of critical congenital heart disease at high altitude? Congenit Heart Dis. 2018;13(6):911-8.

41. Plana MN, Zamora J, Suresh G, Fernandez-Pineda L, Thangaratinam S, Ewer AK. Pulse oximetry screening for critical congenital heart defects. Cochrane Database Syste Rev. 2018;3(3):CD011912-CD.

42. Massin MM, Astadicko I, Dessy H. Noncardiac comorbidities of congenital heart disease in children. Acta paediatr. 2007:96(5):753-5.

43. Neidenbach RC, Lummert E, Vigl M, Zachoval R, Fischereder M, Engelhardt A, et al. Non-cardiac comorbidities in adults with inherited and congenital heart disease: report from a single center experience of more than 800 consecutive patients. Cardiovasc Diagn Ther. 2018;8(4):423-31.

44. Saxena A, Juneja R, Ramakrishnan S. Drug therapy of cardiac diseases in children. Indian Pediatr. 2009:46(4):310-38.

45. Guidelines st. Standard Treatment Guidelines -MOH. In: Mo H, editor Standard treatment guidelines. sixth edit ed: Ghana National Drugs Programme; 2010. p. 99-100.

46. Oakley CM. Does it matter if atrial septal defects are not diagnosed in childhood? Arch Dis Child. 1996;75(2):96-9.

47. Wren C, O'Sullivan JJ. Survival with congenital heart disease and need for follow up in adult life. Heart. 2001;85(4):438-43.

48. Barst RJ, IVy DD, Foreman AJ, McGoon MD, Rosenzweig EB. Four- and seven-year outcomes of patients with congenital heart disease-associated pulmonary arterial hypertension (from the REVEAL registry). Am J Cardiol. 2014;113(1):147-55.

\section{Publisher's Note}

Springer Nature remains neutral with regard to jurisdictional claims in published maps and institutional affiliations.

Ready to submit your research? Choose BMC and benefit from:

- fast, convenient online submission

- thorough peer review by experienced researchers in your field

- rapid publication on acceptance

- support for research data, including large and complex data types

- gold Open Access which fosters wider collaboration and increased citations

- maximum visibility for your research: over $100 \mathrm{M}$ website views per year

At BMC, research is always in progress.

Learn more biomedcentral.com/submissions 